FAUST ZWEITER TEIL 


\author{
Heinz Schlaffer
}

\title{
FAUST ZWEITER TEIL
}

Die Allegorie des 19. Jahrhunderts

\author{
Zweite, um eine Nachbemerkung \\ erweiterte Auflage
}

Verlag J. B. Metzler

Stuttgart - Weimar 


\title{
Die Deutsche Bibliothek - CIP -Einheitsaufnahme
}

\section{Schlaffer, Heinz:}

Faust zweiter Teil : die Allegorie des 19. Jahrhunderts / Heinz Schlaffer. - 2., um eine Nachbemerkung erw. Aufl. Stuttgart ; Weimar : Metzler, 1998

ISBN 978-3-476-01619-5

\author{
ISBN 978-3-476-01619-5 \\ ISBN 978-3-476-03273-7 (eBook) \\ DOI 10.1007/978-3-476-03273-7
}

Dieses Werk ist einschließlich aller seiner Teile urheberrechtlich geschützt. Jede Verwertung außerhalb der engen Grenzen des Urheberrechtsgesetzes ist ohne Zustimmung des Verlages unzulässig und strafbar. Das gilt insbesondere für Vervielfältigungen, Übersetzungen, Mikroverfilmungen und die Einspeicherung in elektronischen Systemen.

(C) 1998 Springer-Verlag GmbH Deutschland

Ursprünglich erschienen bei J.B. Metzlersche Verlagsbuchhandlung und Carl Ernst Poeschel Verlag GmbH in Stuttgart 1998 
Das Buch von Hannelore Schlaffer über Goethes Wilhelm Meister und das von Heinz Schlaffer über Faust II sind komplementär im Kontrast. Für ihre unterschiedlichen Methoden und Ergebnisse sind nicht gegensätzliche Vorentscheidungen der Verfasser, sondern spezifische Anforderungen der poetischen Werke verantwortlich.

Die Wilhelm-Meister-Philologie vertraute bislang dem zeitnahen Vordergrund des Werkes, so daß die Ikonologie seines mythologischen Hintergrunds unentdeckt blieb. Die Faust II-Philologie hielt sich vornehmlich an den mythologisch-symbolischen Apparat und ließ die historischen Bedeutungen unbedacht.

Die vorliegenden Abhandlungen kehren die Richtung der Erkenntnis um: Die Interpretation der Wilhelm-Meister-Romane findet in verborgenen Bildern einen Sinn, der die Prosa des Wirklichen überschreitet. Die Interpretation von Faust II entdeckt die Allegorie als die bildliche Form der Abstraktionen, von denen Goethe das Jahrhundert bestimmt sah.

Die unterschiedlichen Interpretationsverfahren berücksichtigen die historisch begründete Wandlung von Goethes ästhetischer Konzeption. Seine Wilhelm-Meister-Romane waren in der Hoffnung geschrieben, daß Erfahrungen der bürgerlichen Moderne an die Bilder wiederkehrender Mythen zurückzubinden seien. Faust II, Goethes letztes Werk, geht aus der Einsicht hervor, daß die Ansprüche der Moderne seinen Bildervorrat übersteigen und eine neue ästhetische Antwort verlangen. Die Mythen werden von der Allegorie aufgebraucht. Gerade die thematische Nachbarschaft von Wilhelm Meisters Wanderiahren und Faust II macht die geschichtliche Notwendigkeit der poetischen Alternativen bewußt.

H. S., H. S. 
Für einige Hinweise zum Verständnis von Faust II und für die kritische Lektüre des Manuskripts danke ich Doris Kammradt.

H. $S$. 
I. Voraussetzungen ........................ 11

1. Goethe an Schiller, Frankfurt, 16. August 1797 ....... 13

2. Die Kritik der Allegorie im Zeitalter Goethes ......... 29

3. Die Bestimmung der Allegorie in Hegels Ästhetik ...... 39

4. Charaktermasken und Personifikationen in der Kritik der politischen Ökonomie ........................ 49

II. Allegorien und Allegorie in Faust II ............. 63

1. Der Aufzug der Allegorien. Zur Mummenschanz ....... 65

2. Die Entstehung der allegorischen Verhältnisse. Weitläufiger Saal mit Nebengemächern .................... 79

3. Die Gegenwart der Vergangenheit der Antike. Helena ... 99

4. Wissen und Erscheinung. Laboratorium ............. 124

5. Die Form der Allegorie in Faust II $\ldots \ldots \ldots \ldots \ldots \ldots .138$

6. Grenzen der Allegorie. Der Mythos der Natur und die Religion der Liebe ........................ 154

7. Die Sinnlichkeit der Abstraktionen. Zur Ästhetik der Allegorie $\ldots \ldots \ldots \ldots \ldots \ldots \ldots \ldots \ldots \ldots \ldots \ldots . \ldots \ldots$

Schluß. Abstraktion, Allegorie und Realismus .......... 175

Exkurs. Walter Benjamins Allegorie .................. 186

Anmerkungen .............................. 191

Personenregister .............................. 213 